Int. J. Dev. Biol. 49: 285-292 (2005)

doi: $10.1387 / \mathrm{ijdb} .041947 \mathrm{el}$

\title{
The human T cell immune response to Epstein-Barr virus
}

\author{
ELISE LANDAIS, XAVIER SAULQUIN and ELISABETH HOUSSAINT* \\ INSERM U463, Institut de Biologie, Nantes, France
}

\begin{abstract}
The Epstein-Barr virus (EBV) is a gamma-herpes virus which establishes latent, lifelong infection in more than $\mathbf{9 5 \%}$ of the human adult population. Despite its growth transforming capacity, most carriers control EBV associated malignacies efficiently and remain free of EBV+ tumors. Though EBV is controlled by a potent immune response, this virus uses latency to persist in vivo. This review summarizes work which has been done to characterize $T$ cell responses to EBV. The CD8 T cell responses are rather well characterized and have been shown by several groups to be highly focused towards early lytic antigens. Much less is known about CD4 T cell epitopes, due to the small size of the CD4 compartment. However, recent data indicate a control of lytic and latent cycles of EBV by specific CD4+ $T$ cells. A clear understanding of the $T$ cell response to EBV is important with a view to developing immunotherapies for the virus and its related malignancies.
\end{abstract}

KEY WORDS: Epstein-Barr virus, T cell response, EBV-associated tumor

\section{Introduction}

In a way, our interest in immune response to the Epstein-Barr virus (EBV) started with Nicole Le Douarin when, with one of us (E. $H$ ), she investigated cell lineage and tissue interactions in the developing bursa of Fabricius through interspecific chimeras. The distinct morphological differences between the nuclei of the quail and those of the chick were used to determine the origin of cells in differentiated tissues (Le Douarin, 1973). By grafting bursal rudiments of quail into chick and inversely, it was possible to demonstrate that the whole hematopoietic population of the bursa of Fabricius is derived from blood-borne extrinsic precursor cells. The inflow of hemopoietic stem cells takes place between day 7 and 15 in chick embryo. Neither endoderm nor mesoderm of the bursal rudiment is capable of differentiating into lymphoid cells (Le Douarin et al., 1975). Combination of quail bursal endoderm with chick bursal mesenchyme showed that the reticular cells of the follicles are the only endodermal derivatives of the bursa. The mesenchymal bursal component gives rise to the interfollicular connective cells (Houssaint et al., 1976).

A few years later, we became "true" immunologists and we are presently involved in the analysis of T cell responses against EBV. Before describing these responses, we will recall how this common herpesvirus establishes a latent infection in most individuals. Despite a relatively begnin course in most carriers, EBV has growth-transforming capabilities and is causatively linked to three B-cell malignant diseases: endemic Burkitt's lymphoma, Hodgkin's lymphoma and post-transplant lymphoproliferative diseases
(PTLD). Therefore, it appears important to identify the mechanisms whereby healthy EBV carriers avoid development of EBVassociated malignancies.

\section{Infection of humans with EBV}

Epstein-Barr virus is a gammaherpes virus that infects more than $90 \%$ of the human population (see Rickinson and Moss, 1997, for a review). Primary infection often occurs during childhood and is generally asymptomatic (Fleisher et al., 1979). However, adolescents and young adults who experience primary EBV infection frequently present with acute infection mononucleosis (Henle and Henle, 1979). There are two distinct stages of EBV cycle. In latent infection, the genome is maintained at a constant copy number and a limited number of regions of the genome are expressed. In the other stage of infection (lytic cycle), viral DNA is amplified and a variety of viral antigens (lytic antigens) are produced prior to virion maturation (Kieff, 1996). EBV has two major target tissues in vivo, B lymphocytes and squamous pharyngeal epithelium. The virus is transmitted orally and, at the time of primary infection, replicates in cells within the oropharynx, leading to the release of infectious virions at high titers into throat washings (Sixbey etal., 1983). At the same time, EBV establishes

Abbreviations used in this paper: EBV, Epstein-Barr virus; MHC, major histocompatibility complex; PBL, peripheral blood lymphocyte; PTLD, post-transplant lymphoproliferative disease; TNF, tumor necrosis factor.

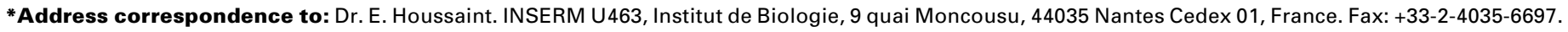
e-mail: chalmeau@nantes.inserm.fr
} 
a latent infection of the $B$ lymphocyte pool that results in lifelong persistence. Entry of EBV into B cells is initiated by an interaction between the major viral envelope glycoprotein gp350 and the Blineage-associated C3d complement receptor CR2. Infection of B lymphocytes with EBV results in persistent latent infection and immortalization of the cells to perpetual proliferation. Following primary infection, a lifelong virus carrier state is established whereby the virus is harbored within a small number of $B$ cells in which most if not all viral latent protein expression is down-regulated (Tierney et al., 1994). In healthy adults, from one to fifty B cells per million in the circulation are infected with EBV and the number of latently infected cells within a person remains stable over years (Babcock et al., 1998). Throughout life, intermittent reactivation of such latently infected B cells into lytic cycle, at mucosal sites probably, underlies the low level shedding of infectious virus detectable in throat washings of asymptomatic virus carriers.

Many of the characteristics of lytic and latent infection in vivo can be studied in vitro with B-LCLs (B lympoblastoid cell lines). These cell lines are established by exogenous EBV infection of $B$ lymphocytes. Of the nearly 100 viral genes that are expressed during replication, only ten are expressed in latently infected $B$ cells in vitro: two types of non translated RNA, six nuclear proteins (EBNA1, 2, 3A, 3B, 3C and EBNA-LP) and two membrane proteins (LMP1, LMP2) (Kieff, 1996). By markedly limiting viral gene expression during latency, EBV reduces the number of viral proteins that permit the recognition of infected cells by $\mathrm{T}$ cell effectors. Lytic cycle can be induced in vitro by different technical approaches, e.g. with phorbol esters. In contrast to the latent phase of infection, when only a limited number of proteins are expressed, activation of the EBV lytic cycle is characterized by the appearance of as many as 80 virus-specific RNA species (see Kieff, 1996, for a review). On the basis of their time of appearance post-induction, these transcripts are designated as immediate early, early or late. The early antigens are composed of a series of polypeptides, such as BZLF1, a replicon activator, BMRF1 and BMLF1, which are both transactivators, BALF5, a DNA polymerase, BORF2 and BARF1, ribonucleotide reductases, BXLF1, a thymidine kinase and BHRF1, a cytoplasmic antigen. EBV late antigens are mostly structural viral proteins which are required for successful packaging of the viral DNA and formation of the virion, among them: the viral capsid antigen, the membrane antigen complex that consists of at least three major EBV-induced glycoproteins, gp350, gp110 and gp85.

\section{EBV is controlled by a potent immune response}

Host immune responses are thought to be of central importance both in limiting the primary infection and in controlling the lifelong virus carrier state. Under normal circonstances and in healthy individuals, EBV infections are not life-threatening and are generally effectively controlled by the immune system through the action of antigen-specific T lymphocytes (see Rickinson and Moss, 1997, for a review). In fact, infection of humans with EBV results in both humoral and cellular immunity to the virus. Although the finding of antibodies directed against viral structural proteins and the EBV nuclear antigens is important for the diagnosis of infection, the cellular immune response is more important for the control of EBV infection. In fact, the high frequency of EBV-associated lymphoproliferative diseases or lymphomas in immunocompromised individuals strongly supports a role for anti-EBV T cells in containing infection (Yao et al., 1996). Both CD8+ and CD4+ T lymphocytes can discriminate EBV-infected or EBV-transformed B cells and, as a consequence, are able to inhibit their growth. EBV-specific T lymphocytes recognize antigens as molecular complexes formed by viral peptide epitopes with molecules of the Major Histocompatibility Complex (MHC), which are expressed on the surface of infected or transformed B lymphocytes. Although EBV-specific $\mathrm{CD}^{+} \mathrm{T}$ cell responses have been well documented, EBV-specific $C D 4^{+} \mathrm{T}$ cell responses have been less well studied.

\section{CD8 T cell response to EBV}

\section{Technical approaches to assess CD8 T cell responses to EBV}

CD8 $T$ cells recognize peptides, derived from endogenous proteins, associated with MHC class I molecules. In the past few years, novel methods for measuring CD8 T cell responses have been applied to a frequency analysis of CD8 T cell responses, namely (i) ELISPOT, which quantitates effector CD8 T cells, based on cytokine release (ii) intracellular cytokine staining and (iii) staining with fluorescent recombinant major histocompatibility complex $(\mathrm{MHC})$ class I-peptide tetramers, which have allowed direct detection and sorting of CD8 $\mathrm{T}$ cells reactive against a defined peptide-MHC class I complex (Altman et al., 1996).

We followed a different approach described in Figure 1, where the screening of anti-EBV responses was based on a transient COS transfection assay allowing a rapid semi-quantitative estimation of $\mathrm{CD}^{+} \mathrm{T}$ cell responses against a large number of HLA/viral protein combinations within polyclonal T cell lines (Scotet et al., 1999). In order to perform a comprehensive analysis of the antigen specificity of EBV-reactive CD8 T cells, we prepared or gathered expression vectors coding for each of the latent EBV proteins or some lytic EBV proteins (BZLF1, BRLF1, BMLF1, BMRF1, BHRF1, BHLF1, BALF2, BALF4, BCRF1 and BLLF1), as well as expression vectors encoding about forty HLA class I molecules. Briefly, COS cells were cotransfected with expression vectors coding for one viral protein and for one of the donor's HLA alleles as described by Boon et al. (Brichard et al., 1993). Transfected COS cells were screened $48 \mathrm{~h}$ after transfection for their ability to stimulate the release of the cytokine Tumor Necrosis Factor (TNF) by CTL, using either clones or polyclonal T cell lines (Espevik and Nissen-Meyer, 1986, Scotet et al., 1996, Scotet et al., 1999).

\section{The CD8 T cell response is highly focused towards early lytic antigens}

Responses to EBV were previously studied by rechallenging peripheral blood lymphocytes (PBL) in vitro with cells of the autologous EBV-transformed $B$ lymphoblastoid cell line (B-LCL), expressing the full range of virus latent proteins (EBNA1, 2, 3A, $3 B, 3 C$ and LP and the two latent membrane proteins LMP1 and LMP2). This led to the conclusion that the dominant responses almost always mapped to epitopes derived from EBNA3A, 3B, or $3 \mathrm{C}$, sometimes accompanied by subdominant responses to one of the other latent proteins, but apparently never to EBNA1 (Murray etal., 1992, Khanna etal., 1995). These observations led to the discovery that endogenously expressed EBNA1 could not be presented to the CD8 T cells because an internal glycinealanine repeat domain protects the protein from a key step in the $\mathrm{MHC}$ class I processing, namely proteasomal degradation to peptides (Levitskaya et al., 1995, Levitskaya et al., 1997). 
During the last five years, we performed an extensive analysis of the CD8 T cell response in healthy donors or in patients. This led us to a conclusion quite different compared to previous studies, as we found that the response is highly focused against proteins generated during the early lytic cycle. Our analysis of CD8 $T$ cell responses to EBV started rather fortuitly with the observation that CD8 T cell clones, originating from the synovial fluid from a patient suffering from rheumatoid arthritis, recognized, in term of proliferation the autologous B-LCL. As the B-LCL had been transformed in vitro by EBV, it was reasonable to think that these CD8 T cell clones recognized EBV epitopes. In fact, a link between EBV and arthritis had long been suspected. To test the hypothesis that the synovial-derived T cell clones could recognize EBV determinants, we prepared a cDNA library from the B-LCL generated from the $B$ lymphocytes of an arthritic patient. With a first CD8 T cell clone, that was restricted through HLA-A2, we screened this cDNA library, using the COS assay and we could thus demonstrate that this clone recognized the early lytic EBV protein BMLF1, in the HLA-A2 context. We then extended our analysis and we showed that most CD8 T cell clones in the joint fluid from a patient suffering from rheumatoid arthritis recognized either BZLF1 or BMLF1, two transactivating proteins produced early in the lytic cycle of EBV (Scotet et al., 1996).

To assess the generality of this observation and its relevance to autoimmunity, we performed an extensive screening of CD8 T cell responses to EBV within polyclonal T cell lines derived from the synovial fluid from a large number of patients suffering from various forms of chronic arthritis or other inflammatory diseases $(n=32)$ and we compared these responses to those observed among PBL of healthy virus carriers $(n=10)$ or kidney recipients $(n=16)$. For each donor, the amount of TNF released by the polyclonal $T$ cell line was assessed following incubation with COS cells cotransfected with DNA coding for some of the patient HLA class I alleles and with cDNA coding for one EBV protein (18 EBV cDNAs were included in the assay).

Responses against one or several EBV proteins were detected in about $2 / 3$ of the samples analysed. In fact, in accordance with others (Murray et al., 1992, Khanna et al., 1995), we found that most individuals had CTL responses to more than one EBV antigen (Scotet etal., 1999). Irrespective of the physiopathological status of the donor, these responses were mainly directed against the immediate early or early lytic proteins: BZLF1, BRLF1 and BMLF1. For example, a response to BZLF1 was found for $60 \%$ of the donors. Moreover, the high amounts of TNF produced by the CD8 T cells responding to BZLF1 suggested a high frequency of responding cells. This was later on corroborated by tetramer analysis, that showed that as many as $15 \%$ of synovial CD8 T cells reacted against a single BZLF1 epitope in some samples (Tan et al., 2000). Weaker responses to some latent EBV proteins, namely EBNA3A, 3B, 3C and LMP2, were observed in 10 to $20 \%$ donors. The fact that we did not observe any anti-EBV response in $1 / 3$ of donors does not necessarily mean that these donors were not responding to EBV. In fact, we only tested responses in the context of HLA class I molecules for which cDNA were available and in several instances, the HLA subtypes were not precisely identified, so that in some cases we used inappropriate HLA cDNA.

Two main conclusions could be drawn from this extensive analysis. With regard to anti-EBV CD8 T cell responses, our data showed that they are highly focused against early lytic antigens. The COS transfection assay is not sensitive enough to detect subdominant responses but it allows a rapid identification of the major epitopes. Concerning a possible link between EBV and rheumatoid arthritis, we have shown that the presence of EBV-specific T cells within inflammed lesions of patients suffering from autoimmune diseases is a general phenomenon. In fact, we observed an enrichment for EBV-specific CD8 T cells in all the inflammatory sites that we examined and these responses showed the same specificity patterns as those of memory responses occurring in long term virus carriers. Enrichment in CD8 T cells responding to EBV in the inflammatory sites rather reflects an unspecific trapping of activated $\mathrm{T}$ cells under chronic inflammation than an initiation of the autoimmune process by the virus.

Concurrently to our study, different groups reevaluated CD8 T cell responses to EBV by using novel methods of estimating frequencies of antigen-specific T cells. These included assays to
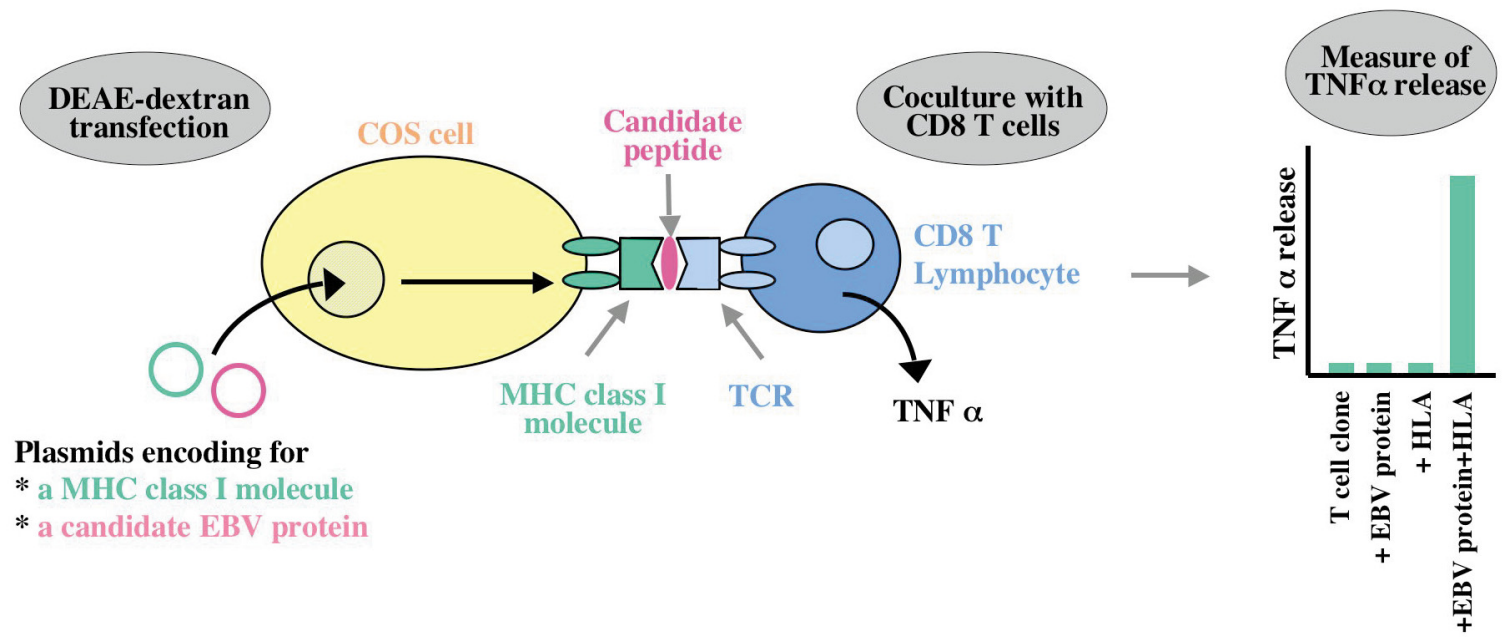

Fig. 1. Rationale of the COS transfection assay used to detect anti-EBV T cell responses of CD8 $\mathbf{T}$ cell clones. In a first step, COS cells were co-transfected with plasmids encoding an appropriate MHC class I molecule and an EBV protein. After 48 h hours, the CD8 T cell clone was added to transfected COS cells and its activation state was evaluated on the basis of TNF- $\alpha$ production. TNF production was observed only when the T cell clone recognized onto COS cells the appropriate EBV protein plus the relevant MHC class I molecule. 
detect IFN- $\gamma$ release from epitope-specific CD8 ${ }^{+} \mathrm{T}$ cells following peptide stimulation (Lalvani et al., 1997) and the use of tetrameric MHC-peptide complexes to directly stain T cells of the appropriate specificity (Altman et al., 1996). Results obtained using these techniques have led to a reevaluation of the nature of both primary and memory responses to EBV virus (Steven et al., 1997, Callan et al., 1998, Tan et al., 1999). This revealed a surprisingly high frequency of circulating CD8 T cells specific for individual EBV proteins in healthy seropositive carriers (Tan et al., 1999). During acute infection up to $40 \%$ of the total CD8 ${ }^{+}$cells in the blood are directed against a single lytic EBV protein epitope, while up to $2 \%$ of the $\mathrm{CD}^{+}$cells are directed against a single latent protein epitope (Callan et al., 1998).

Immunodominant EBV epitopes recognized by CD8 T cells

All along this study, we screened for anti-EBV responses in 35 EBV-reactive CD8 T cell lines against a large set of 18 EBV proteins in the context of 19 HLA alleles (Saulquin et al., 2000). Such a large scale analysis revealed an unexpectedly focalized response against few EBV protein/HLA combinations (nearly half of them were derived from BZLF1). Once we had determined the EBV proteins that were recognized by EBV-specific $\mathrm{CD}^{+} \mathrm{T}$ cell clones, we defined the precise EBV epitope (8 to 11 amino-acid sequence) that activated these clones by using a library of overlapping EBV peptides. To this end, we studied the responses of polyclonal $T$ cell lines and/or T cell clones against sets of 23residue peptides spanning the whole viral proteins. The sequence of the minimal peptide was then deduced from their consensus binding capacities to the relevant HLA molecule (Rammensee et al., 1995). As expected from earlier studies (see Rickinson and Moss, 1997, for a review), responses elicited by the above combinations were in almost all cases directed against a single peptidic antigen. Many of these epitopes were frequently recognized by distinct individuals sharing the corresponding HLA allele (Table I). For instance BZLF1/B8 and BZLF1/B35 combinations were recognized by all the EBV-reactive cell lines

Sorting with multimers



bearing the appropriate HLA and BMLF1/A2, EBNA3B/A11, $B Z L F 1 / B 8, E B N A 3 A / B 27$ were recognized by a large proportion of the cell lines bearing the corresponding HLA. HLA-B allelerestricted CTL epitopes appear to be more dominant than HLA-A allele-restricted epitopes. As suggested by others (Khanna et al., 1995), HLA-B alleles may be in general more efficient than HLA$A$ alleles in their loading and transport of viral peptides.

\section{CD4 T cell response to EBV}

Much less is known about the CD4+ $\mathrm{T}$ cell responses to EBV, although there is an increasing awareness of their key role in 1) supporting high affinity antibody production 2) initiating and particularly, maintaining CTL numbers and function and 3) performing direct effector activity. Analysis of CD4 T cell responses has been greatly hampered by the small size of the CD4 compartment. No CD4 T cell expansions have been detected, even during the early stages of EBV acute infection (Maini et al., 2000).

\section{Strategies for the identification of CD4 T cell responses to EBV}

$\mathrm{CD}^{+}{ }^{+} \mathrm{T}$ cells recognize a peptide bound to $\mathrm{MHC}$ class II molecules on the cell surface of antigen presenting cells. The formation of MHC class II-peptide complexes on the cell surface is a complicated, multistep, process that favors presentation of antigens derived from exogenous proteins. This process occurs in antigen presenting cells. Therefore, the COS transfection assay is not applicable to characterize CD4 T cell epitopes as COS cells do not have the machinary required for MHC class II processing. Several technical approaches have been used by different groups to characterize CD4 T cell responses to EBV. Autologous B-LCL or dendritic cells were infected with recombinant vaccinia virus (rVV) encoding individual lytic or latent protein. Alternatively, the EBV protein, particularly EBNA1, was delivered to dendritic cells as recombinant protein. The response of CD4 T cell clones or $\mathrm{T}$ cell lines was then evaluated on the basis of cytokine production (IFN- $\gamma$ or TNF- $\alpha$ ). Once the EBV protein

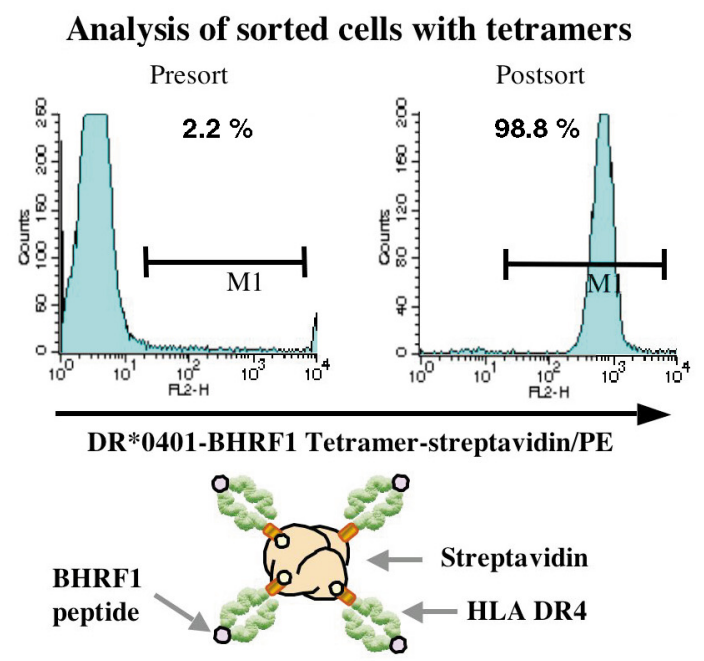

Fig. 2. Efficient sorting of BHRF1-specific CD4 T cells by using magnetic beads covered with multiple DR*0401 monomers loaded with the BHRF1 $_{\mathbf{1 2 2 - 1 3 3}}$ peptide. After a 2-week culture, the frequency of BHRF1-specific cells among the sorted cells was estimated by staining with the relevant tetramer. Phycoerythrin (PE)-labeled streptavidin was used to produce fluorescent DR*0401 tetramers loaded with BHRF1 peptide. In the experiment described here, while only $2 \%$ of BHRF1-specific CD4 T cells were present within the polyclonal T cell line, nearly all the cells sorted with BHRF1 multimers were BHRF1-specific. 




Fig. 3. Features of the CD8 and CD4 T cell responses to EBV from a compilation of data from different groups. The length of the bar gives an idea of the dominance of the response. The HLA restriction of the responses that have been described for a given EBV protein is indicated. Abbreviations: IE, immediate early; E, early; L, late lytic protein; E1, E2, E3A, E3B, E3C and ELP represent EBNA1, 2, 3A, 3B, 3C and LP.

identified, sets of overlapping peptides spanning different EBV proteins were used to define precisely the epitope recognized, through IFN- $\gamma$ release by activated CD4 T cells. Some groups used only the second step, that is, systematic screening of overlapping synthetic peptides. To identify the EBV protein recognized by a given $C D 4^{+} \mathrm{T}$ cell clone, we co-cultured this CD4 $T$ cell clone for a few hours with the B-LCL from the same donor, hence sharing the appropriate MHC class II alleles, infected with individual recombinant vaccinia virus encoding 10 lytic and all latent EBV proteins. Activation of the clone was then evaluated both in terms of cytotoxicity and of TNF- $\alpha$ production assay. The precise epitope was defined in a second step by using the set of overlapping peptides covering the whole sequence of that protein.

\section{CD4 $T$ cell recognition of lytic and latent EBV proteins}

As we had observed an enrichment for EBV-specific CD8 T cells in the joint of patients suffering from rheumatoid arthritis, we started from several CD4 T cell clones derived from synovial fluid samples to attempt characterizing CD4 T cell responses to EBV. One of these clones recognized an epitope derived from BHRF1, a protein produced during the early stages of the EBV lytic cycle, in the HLA$\mathrm{DR}^{*} 0401$ context. We will summarize here the identification and the functional characteristics of this response. The CD4 T cell clone was activated by the autologous B-LCL infected with the rVV encoding BHRF1, as documented by TNF- $\alpha$ production. In contrast, the B-LCL infected by rVV encoding 16 other EBV proteins was not recognized by that clone. The epitope recognized by this clone $\left(\mathrm{BHRF}_{122-133}\right)$, was identified through screening of synthetic overlapping peptides covering the entire BHRF1 sequence and the HLA-restriction of this clone was found to be HLA-DR*0401. We then wanted to investigate whether $\mathrm{BHRF}_{122-133}-$ specific $\mathrm{T}$ cells could be found within polyclonal $T$ cell lines derived either from HLA-DR*0401+donors. Peptide-MHC class I multimeric complexes had revealed efficient tools to detect and to sort out rare specific 
CD8 $T$ cell populations. Thus we thought using a similar strategy to sort out CD4 T cells. To this end, recombinant DRA $1{ }^{*} 0101 /$ DRB $1{ }^{*} 0401$ monomers loaded with the $\mathrm{BHRF}_{122-133}$ peptide were produced by the group of William Kwok (Novak et al., 1999, Novak et al., 2001) and we performed immunomagnetic sorting using streptavidin beads coated with biotinylated DRB1*0401-BHRF ${ }_{122-}$ ${ }_{133}$ monomers (hereafter referred to as multimers) (Fig. 2). After a 2-week culture under polyclonal activation, response of the sorted cells to the $\mathrm{BHRF}_{122-133}$ peptide was tested either by staining with the tetramer or by functional assays (TNF production, cytotoxic assay). Successful sorting of BHRF1-specific cells was achieved for all $T$ cell lines derived from DRB $1{ }^{*} 0401$ individuals (be they derived from the peripheral blood of healthy virus carriers or from the synovial fluid of arthritis patients), indicating that the response to BHRF1 is not specifically linked to artritis. The expanded CD4 T cells were nearly $100 \%$ specific to BHRF1, thus underlying the efficiency of this sorting approach with DR4 multimers (Fig. 2).

Functional analysis of BHRF1-specific CD4 $\mathrm{T}$ cell clones demonstated their cytolytic action against $\mathrm{DR}^{\star} 0401^{+} \mathrm{EBV}$ transformed B-LCL and potent IFN- $\gamma$ production, thus suggesting that this CD4 T cell population could contribute to the control of EBV replication. The consistent killing of B-LCL, with $40-80 \%$ killing efficiency, was rather surprising, as about $5 \%$ of cells within a $B$ $\mathrm{LCL}$ are expected to express lytic EBV proteins. Analysis of killing mechanism will need further investigation. These data show that it is possible to efficiently sort out and expand CD4 T cells specific for defined epitopes. Such peptide/MHC class II multimer sorting strategy could be of potential therapeutic interest for the immunotherapy of viral infections or cancers.

The CD4 T cell response to EBV was also documented by other groups. EBV specificity of some CD4+ ${ }^{+} \mathrm{T}$ cell clones had been previously reported (Wallace et al., 1991, Khanna et al., 1995, White et al., 1996, Khanna et al., 1997). In more recent systematic analysis, using polyclonal CD4 ${ }^{+} \mathrm{T}$ cell lines, the nuclear antigen EBNA1 was found to be a main EBV latency antigen for CD4+ $\mathrm{T}$ cells (Munz et al., 2000, Leen et al., 2001, Paludan et al., 2002). During primary infection, it was shown that up to $2.7 \%$ of circulating effector/memory CD4+ T cells are EBV-specific (Precopio et al., 2003). Responses to BZLF1, BMLF1 and EBNA3A were more commonly detected than responses to EBNA1 in patients with infectious mononucleosis (Precopio et al., 2003). A compilation of the CD4 T cell responses to EBV, compared to EBV-specific CD8 $\mathrm{T}$ cell responses, is presented in Fig. 3.

An interesting feature of some of the CD4 T clones, that have been described to respond to EBV antigens, is that they kill the autologous B-LCL with a rather high efficiency (Paludan et al., 2002) or they inhibit B-LCL proliferation (Omiya et al., 2002). Moreover, it has been shown that several EBV epitopes recognized in the MHC class II context are highly "promiscuous", as they are restricted by numerous different MHC class II alleles. This indicates that these peptides could be recognized by a large proportion of the general population. This could help designing widely applicable peptide-based vaccine to prevent and perhaps treat PTLD in transplant patients.

\section{EBV virus uses latency to persist in vivo}

Despite an efficient control of the immune system, EBV persistslifelong. How can one explain that the immune system does not succeed in eliminating the virus? The EBV persistence in memory $B$ cells in vivo has been recently revisited by the group of Thorley-Lawson (Babcock et al., 2000, Kurth et al., 2000, Thorley-Lawson, 2001). In fact, EBV-infected B cells in vivo can express four different programs of gene usage depending on the location and the differentiation state of the infected B cell. One of these programs is used to produce infectious virus. The other three are all associated with latent infection, in which no infectious virus is produced: $i)$ the growth program, also called latency III, in which all nine latent proteins are expressed ii) the default program, or latency II, in which a restricted set of three latent proteins are expressed and iii) the latency program (latency I), in which few, if any latent genes are expressed. The virus uses the latency program to persist in vivo in a transcriptionally quiescent state (Tierney et al., 1994, Babcock et al., 1998) within resting memory B cells that circulate in the peripheral blood (Babcock et al., 1998, Babcock et al., 1999, Thorley-Lawson, 2001). These resting B cells express none of the EBV proteins (the transcripts for LMP2 are often detected in these cells) and they exhibit a particular phenotype of resting memory cells (IgD-, CD27+, CD5-), which ensures escape from immune surveillance. In this fashion $>95 \%$ of all adults are infected beningly for life. Persistent infection is characterized by stable numbers of latently infected $B$ cells in the blood ( 0.5 to 50 per million, depending on the individual) and the steady shedding of infectious virus into saliva. In this way, a balance between rare EBV-harboring $B$ cells and EBV-specific $T$ cells is established during persistence of the virus and the virus is continuously monitored by the immune system.

\section{EBV-associated diseases}

EBV has potent B-cell transforming activity and is causatively linked or associated with various B-cell malignant diseases: endemic Burkitt's lymphoma, Hodgkin's Iymphoma, nasopharyngeal carcinoma and post-transplant lymphoproliferative disease (PTLD). All four types of tumour have distinct cellular phenotypes and patterns of EBV gene expression, suggesting that the pathogenetic role of the virus might be different in each case. EBV-transformed cells exhibit one of three latency types distinguished from each other by the panel of expressed EBV antigens (Kieff, 1996). In Burkitt's lymphoma, only EBNA1 is expressed (latency I). In nasopharyngeal carcinoma (latency II), LMP1 and LMP2, as well as EBNA1, are expressed. Only in latency III immunoblastic lymphomas, are the nine latent proteins expressed, particularly the highly immunogenic EBNA3A, $\mathrm{B}$ and $\mathrm{C}$.

As documented in part 2, EBV-specific $\mathrm{CD}^{+}$and $\mathrm{CD}^{+}{ }^{+} \mathrm{T}$ cell responses are preferentially directed towards the early lytic proteins and, to a lesser extent, towards the nuclear antigens, EBNA3A, EBNA3B and EBNA3C, which are not expressed in most EBVassociated malignancies. EBNA1 appears as an optimal EBVspecific antigen because it must be expressed in all proliferating EBV-infected cells to maintain the viral episome. Therefore, all EBV-induced tumors express this foreign antigen. The problem is that EBNA1 is invisible to CD8 ${ }^{+}$cytotoxic T lymphocytes because its Gly/Ala repeat domains prevents proteasome-dependent processing for presentation on MHC class I (Levitskaya et al., 1995, 1997). Therefore, many EBV-associated malignancies do not seem to provide good targets for the dominant EBV-specific 
CD8 $T$ cell response. The recent finding that $\mathrm{CD}^{+} \mathrm{T}$ cells consistently respond to EBNA1 suggests that EBNA1-specific $\mathrm{CD}^{+} \mathrm{T}$ cells provide resistance to the development of Burkitt's lymphoma, Hodgkin's and other EBV-associated malignancies. Likewise, these new data suggest that EBNA1 be tested as an antigen to prevent and treat such malignancies.

The question is different for the posttransplant lymphoproliferative disorders (PTLD). In immunosuppressed individuals, such as transplant patients, primary EBV infection usually results in PTLD that often progress into $B$ cell lymphomas£(Hsieh et al., 1999, Paya et al., 1999, Hopwood and Crawford, 2000). Current prophylactic and therapeutic approaches for PTLD and lymphomas are far from optimal. The reduction of immunosuppressive therapy facilitates the immune-mediated viral elimination, but with a high risk of organ rejection and the use of antiviral agents is of unclear effectiveness (Paya et al., 1999). Results obtained using anti-CD20 mAb (CD20 is a differenciation marker of B lymphocytes) therapy appear promising, but have the disadvantage of long term $B$ cell depletion and the occurrence of CD20-negative relapses (Faye et al., 2001, Zilz et al., 2001, Verschuuren et al., 2002). One of the most effective ways to prevent or treat PTLD and B cell lymphomas is via adoptive immunotherapy using EBV-specific T lymphocytes (Heslop and Rooney, 1997, Rooney et al., 1998), but this approach is labor intensive, costly and not widely available. An alternative approach would be to use synthetic peptides, representing EBV CD8 or CD4 T cell epitopes, to stimulate in vivo responding T lymphocytes. Such a vaccine is not yet available.

\section{Acknowledgements}

This work was supported in part by the Association pour la Recherche surla Polyarthrite (ARP), the Ligue Nationale Contre Le Cancer (LNCC), the Centre Hospitalier Universitaire de Nantes and by institutional grants from INSERM.

\section{References}

ALTMAN, J.D., MOSS, P.A.H., GOULDER, P.J.R., BAROUCH, D.H., MCHEYZERWILLIAMS, M.G., BELL, J.I., MCMICHAEL, A.J. and DAVIS, M.M. (1996). Phenotypic analysis of antigen-specific T lymphocytes. Science 274: 94-96.

BABCOCK, G.J., DECKER, L.L., VOLK, M. and THORLEY-LAWSON, D.A. (1998). EBV persistence in memory B cells in vivo. Immunity 9: 395-404.

BABCOCK, G.J., DECKER, L.L., FREEMAN, R.B. and THORLEY-LAWSON, D.A. (1999). Epstein-barr virus-infected resting memory B cells, not proliferating lymphoblasts, accumulate in the peripheral blood of immunosuppressed patients. J. Exp. Med. 190: 567-576.

BABCOCK, G.J., HOCHBERG, D. and THORLEY-LAWSON, A.D. (2000). The expression pattern of Epstein-Barr virus latent genes in vivo is dependent upon the differentiation stage of the infected B cell. Immunity 13: 497-506.

BRICHARD, V., VAN PEL, A., WOLFEL, T., WOLFEL, C., DE PLAEN, E., LETHE, B., COULIE, P. and BOON, T. (1993). The tyrosinase gene codes for an antigen recognized by autologous cytolytic T lymphocytes on HLA-A2 melanomas. $J$. Exp. Med. 178: 489-495.

CALLAN, M.F., TAN, L., ANNELS, N., OGG, G.S., WILSON, J.D., O'CALLAGHAN, C.A., STEVEN, N., MCMICHAEL, A.J. and RICKINSON, A.B. (1998). Direct visualization of antigen-specific CD8+ $T$ cells during the primary immune response to Epstein-Barr virus In vivo. J. Exp. Med. 187: 1395-1402.

ESPEVIK, T. and NISSEN-MEYER, J. (1986). A highly sensitive cell line, WEHI 164 clone 13, for measuring cytotoxic factor/tumor necrosis factor from human monocytes. J. Immunol. Methods 95: 99-105.

FAYE, A., QUARTIER, P., REGUERRE, Y., LUTZ, P., CARRET, A.S., DEHEE, A., ROHRLICH, P., PEUCHMAUR, M., MATTHIEU-BOUE, A., FISCHER, A. and
VILMER, E. (2001). Chimaeric anti-CD20 monoclonal antibody (rituximab) in post-transplant B-lymphoproliferative disorder following stem cell transplantation in children. Br. J. Haematol. 115: 112-118.

FLEISHER, G., HENLE, W., HENLE, G., LENNETTE, E.T. and BIGGAR, R.J. (1979). Primary infection with Epstein-Barr virus in infants in the United States: clinical and serologic observations. J. Infect. Dis. 139: 553-558.

HENLE, G. and HENLE, W. (1979). The virus as the etiologic agent of infectious mononucleosis. In the Epstein-Barr Virus. B. G. Achong, ed. Springer, Berlin:297.

HESLOP, H.E. and ROONEY, C.M. (1997). Adoptive cellular immunotherapy for EBV lymphoproliferative disease. Immunol. Rev. 157: 217-222.

HOPWOOD, P. and CRAWFORD, D.H. (2000). The role of EBV in post-transplant malignancies: a review. J. Clin. Pathol. 53: 248-254.

HOUSSAINT, E., BELO, M. and LE DOUARIN, N.M. (1976). Investigations on cell lineage and tissue interactions in the developing bursa of Fabricius through interspecific chimeras. Dev. Biol. 53: 250-264.

HSIEH, W.S., LEMAS, M.V. and AMBINDER, R.F. (1999). The biology of Epstein-Barr virus in post-transplant lymphoproliferative disease. Transpl. Infect. Dis. 1:204-212.

KHANNA, R., BURROWS, S.R., STEIGERWALD-MULLEN, P.M., THOMSON, S.A., KURILLA, M.G. and MOSS, D.J. (1995). Isolation of cytotoxic T lymphocytes from healthy seropositive individuals specific for peptide epitopes from Epstein-Barr virus nuclear antigen 1: implications for viral persistence and tumor surveillance. Virology 214: 633-637.

KHANNA, R., BURROWS, S.R., THOMSON, S.A., MOSS, D.J., CRESSWELL, P., POULSEN, L.M. and COOPER, L. (1997). Class I processing-defective Burkitt's lymphoma cells are recognized efficiently by CD4+ EBV-specific CTLs. J. Immunol. 158: 3619-3625.

KIEFF, E. (1996). Epstein-Barr virus and its replication. In Field Virology. Third Edition. Edited by Fields B.N., Knipe, D.M., Holwey, P.M.,et al. Philadelphia: Lipincott-Raven Publishers, pp. 2243-2395.

KURTH, J., SPIEKER, T., WUSTROW, J., STRICKLER, G.J., HANSMANN, L.M., RAJEWSKY, K. and KUPPERS, R. (2000). EBV-infected B cells in infectious mononucleosis: viral strategies for spreading in the B cell compartment and establishing latency. Immunity 13: 485-495.

LALVANI, A., BROOKES, R., HAMBLETON, S., BRITTON, W.J., HILL, A.V. and MCMICHAEL, A.J. (1997). Rapid effector function in CD8+ memory T cells. J. Exp. Med. 186: 859-865.

LE DOUARIN, N. (1973). A biological cell labeling technique and its use in expermental embryology. Dev. Biol. 30: 217-222.

LE DOUARIN, N.M., HOUSSAINT, E., JOTEREAU, F.V. and BELO, M. (1975). Origin of hemopoietic stem cells in embryonic bursa of Fabricius and bone marrow studied through interspecific chimeras. Proc. Natl. Acad. Sci. U S A 72: 2701-2705.

LEEN, A., MEIJ, P., REDCHENKO, I., MIDDELDORP, J., BLOEMENA, E., RICKINSON, A. and BLAKE, N. (2001). Differential immunogenicity of EpsteinBarr virus latent-cycle proteins for human CD4(+) T-helper 1 responses. J. Virol. 75: 8649-8659.

LEVITSKAYA, J., CORAM, M., LEVITSKY, V., IMREH, S., STEIGERWALDMULLEN, P.M., KLEIN, G., KURILLA, M.G. and MASUCCI, M.G. (1995). Inhibition of antigen processing by the internal repeat region of the Epstein-Barr virus nuclear antigen-1. Nature 375: 685-688.

LEVITSKAYA, J., SHARIPO, A., LEONCHIKS, A., CIECHANOVER, A. and MASUCCI, M.G. (1997). Inhibition of ubiquitin/proteasome-dependent protein degradation by the Gly-Ala repeat domain of the Epstein-Barr virus nuclear antigen 1. Proc. Natl. Acad. Sci. US A 94: 12616-12621.

MAINI, M.K., GUDGEON, N., WEDDERBURN, L.R., RICKINSON, A.B. and BEVERLEY, P.C. (2000). Clonal expansions in acute EBV infection are detectable in the CD8 and not the CD4 subset and persist with a variable CD45 phenotype. J. Immunol. 165: 5729-5737.

MUNZ, C., BICKHAM, K.L., SUBKLEWE, M., TSANG, M.L., CHAHROUDI, A., KURILLA, M.G., ZHANG, D., O'DONNELL, M. and STEINMAN, R.M. (2000). Human CD4(+) T lymphocytes consistently respond to the latent Epstein-Barr virus nuclear antigen EBNA1. J. Exp. Med. 191: 1649-1660.

MURRAY, R.J., KURILLA, M.G., BROOKS, J.M., THOMAS, W.A., ROWE, M., KIEFF, E. and RICKINSON, A.B. (1992). Identification of target antigens for the human cytotoxic T cell response to Epstein-Barr virus (EBV): implications for the immune control of EBV-positive malignancies. J. Exp. Med. 176: 157-168. 
NOVAK, E.J., LIU, A.W., NEPOM, G.T. and KWOK, W.W. (1999). MHC class II tetramers identify peptide-specific human CD4(+) T cells proliferating in response to influenza A antigen [see comments]. J. Clin. Invest. 104: R63-67.

NOVAK, E.J., LIU, A.W., GEBE, J.A., FALK, B.A., NEPOM, G.T., KOELLE, D.M. and KWOK, W.W. (2001). Tetramer-guided epitope mapping: rapid identification and characterization of immunodominant CD4+ T cell epitopes from complex antigens. J. Immunol. 166: 6665-6670.

OMIYA, R., BUTEAU, C., KOBAYASHI, H., PAYA, C.V. and CELIS, E. (2002). Inhibition of EBV-induced lymphoproliferation by CD4(+) T cells specific for an MHC class II promiscuous epitope. J. Immunol. 169: 2172-2179.

PALUDAN, C., BICKHAM, K., NIKIFOROW, S., TSANG, M.L., GOODMAN, K., HANEKOM, W.A., FONTENEAU, J.F., STEVANOVIC, S. and MUNZ, C. (2002). Epstein-Barr nuclear antigen 1-specific CD4(+) Th1 cells kill Burkitt's lymphoma cells. J. Immunol. 169: 1593-1603.

PAYA, C.V., FUNG, J.J., NALESNIK, M.A., KIEFF, E., GREEN, M., GORES, G., HABERMANN, T.M., WIESNER, P.H., SWINNEN, J.L., WOODLE, E.S. and BROMBERG, J.S. (1999). Epstein-Barr virus-induced posttransplant lymphoproliferative disorders. ASTS/ASTP EBV-PTLD Task Force and The Mayo Clinic Organized International Consensus Development Meeting. Transplantation 68: 1517-1525.

PRECOPIO, M.L., SULLIVAN, J.L., WILLARD, C., SOMASUNDARAN, M. and LUZURIAGA, K. (2003). Differential kinetics and specificity of EBV-specific CD4+ and CD8+ T cells during primary infection. J. Immunol. 170: 2590-2598.

RAMMENSEE, H.G., FRIEDE, T. and STEVANOVIIC, S. (1995). MHC ligands and peptide motifs: first listing. Immunogenetics 41: 178-228.

RICKINSON, A.B. and MOSS, D.J. (1997). Human cytotoxic T lymphocyte responses to Epstein-Barr virus infection. Annu. Rev. Immunol. 15: 405-431.

ROONEY, C.M., SMITH, C.A., NG, C.Y., LOFTIN, S.K., SIXBEY, J.W., GAN, Y., SRIVASTAVA, D.K., BOWMAN, L.C., KRANCE, R.A., BRENNER, M.K. and HESLOP, H.E. (1998). Infusion of cytotoxic T cells for the prevention and treatment of Epstein-Barr virus-induced lymphoma in allogeneic transplant recipients. Blood 92: 1549-1555.

SAULQUIN, X., IBISCH, C., PEYRAT, M.A., SCOTET, E., HOURMANT, M., VIE, H., BONNEVILLE, M. and HOUSSAINT, E. (2000). A global appraisal of immunodominant CD8 $T$ cell responses to Epstein-Barr virus and cytomegalovirus by bulk screening. Eur. J. Immunol. 30: 2531-2539.

SCOTET, E., DAVID-AMEline, J., PEYRAT, M.A., MOREAU-AUBRY, A., PINCZON, D., LIM, A., EVEN, J., SEMANA, G., BERTHELOT, J.M., BREATHNACH, R., BONNEVILLE, M. and HOUSSAINT, E. (1996). T cell response to Epstein-Barr virus transactivators in chronic rheumatoid arthritis. J. Exp. Med. 184: 1791-1800.

Scotet, E., PEYRAT, M.A., SAUlquin, X., Retiere, C., COUEdel, C., DAVODEAU, F., DULPHY, N., TOUBERT, A., BIGNON, J.D., LIM, A., VIE, H., HALLET, M.M., LIBLAU, R., WEBER, M., BERTHELOT, J.M., HOUSSAINT, E. and BONNEVILLE, M. (1999). Frequent enrichment for CD8 T cells reactive against common herpes viruses in chronic inflammatory lesions: towards a reassessment of the physiopathological significance of T cell clonal expansions found in autoimmune inflammatory processes. Eur. J. Immunol. 29: 973-985.

SIXBEY, J.W., VESTERINEN, E.H., NEDRUD, J.G., RAAB-TRAUB, N., WALTON, L.A. and PAGANO, J.S. (1983). Replication of Epstein-Barr virus in human epithelial cells infected in vitro. Nature 306: 480-483.

STEVEN, N.M., ANNELS, N.E., KUMAR, A., LEESE, A.M., KURILLA, M.G. and RICKINSON, A.B. (1997). Immediate early and early lytic cycle proteins are frequent targets of the Epstein-Barr virus-induced cytotoxic T cell response. J. Exp. Med. 185: 1605-1617.

TAN, L.C., GUDGEON, N., ANNELS, N.E., HANSASUTA, P., O'CALLAGHAN, C.A., ROWLAND-JONES, S., MCMICHAEL, A.J., RICKINSON, A.B. and CALLAN, M.F. (1999). A re-evaluation of the frequency of CD8+ T cells specific for EBV in healthy virus carriers. J. Immunol. 162: 1827-1835.

TAN, L.C., MOWAT, A.G., FAZOU, C., ROSTRON, T., ROSKELL, H., DUNBAR, P.R., TOURNAY, C., ROMAGNE, F., PEYRAT, M.A., HOUSSAINT, E., BONNEVILLE, M., RICKINSON, A.B., MCMICHAEL, A.J. and CALLAN, M.F. (2000). Specificity of T cells in synovial fluid: high frequencies of CD8(+) T cells that are specific for certain viral epitopes. Arthritis. Res. 2: 154-164.

THORLEY-LAWSON, D.A. (2001). Epstein-Barr virus: exploiting the immune system. Nat. Rev. Immunol. 1: 75-82.

TIERNEY, R.J., STEVEN, N., YOUNG, L.S. and RICKINSON, A.B. (1994). EpsteinBarr virus latency in blood mononuclear cells: analysis of viral gene transcription during primary infection and in the carrier state. J. Virol. 68: 7374-7385.

VERSCHUUREN, E.A., STEVENS, S.J., VAN IMHOFF, G.W., MIDDELDORP, J.M., DE BOER, C., KOETER, G., THE, T.H. and VAN DER BIJ, W. (2002). Treatment of posttransplant lymphoproliferative disease with rituximab: the remission, the relapse and the complication. Transplantation 73: 100-104.

WALLACE, L.E., WRIGHT, J., ULAETO, D.O., MORGAN, A.J. and RICKINSON, A.B. (1991). Identification of two T-cell epitopes on the candidate Epstein-Barr virus vaccine glycoprotein gp340 recognized by CD4+ T-cell clones. J. Virol. 65: 3821-3828.

WHITE, C.A., CROSS, S.M., KURILLA, M.G., KERR, B.M., SCHMIDT, C., MISKO, I.S., KHANNA, R. and MOSS, D.J. (1996). Recruitment during infectious mononucleosis of CD3+CD4+CD8+ virus- specific cytotoxic T cells which recognise Epstein-Barr virus lytic antigen BHRF1. Virology 219: 489-492.

YAO, Q.Y., TIERNEY, R.J., CROOM-CARTER, D., DUKERS, D., COOPER, G.M., ELLIS, C.J., ROWE, M. and RICKINSON, A.B. (1996). Frequency of multiple Epstein-Barr virus infections in T-cell- immunocompromised individuals. $J$. Virol. 70: 4884-4894.

ZILZ, N.D., OLSON, L.J. and MCGREGOR, C.G. (2001). Treatment of posttransplant lymphoproliferative disorder with monoclonal CD20 antibody (rituximab) after heart transplantation. J. Heart Lung Transplant. 20: 770-772. 